\title{
The Effects of $\mathrm{NaOH}$ Concentration on the Hydrothermal Synthesis of a Hydroxyapatite-Zeolite Composite Using Blast Furnace Slag
}

\author{
G. U. Ryu ${ }^{1}$, Hammad R. Khalid ${ }^{2} \mathbb{1}$, Namkon Lee ${ }^{3}$, Zhen Wang ${ }^{1}$ and H. K. Lee ${ }^{1, *}$ \\ 1 Department of Civil and Environmental Engineering, Korea Advanced Institute of Science and Technology, \\ Guseong-dong, Yuseong-gu, Daejeon 34141, Korea; fbrmsdn@kaist.ac.kr (G.U.R.); jeanw@kaist.ac.kr (Z.W.) \\ 2 Civil and Environmental Engineering Department, King Fahd University of Petroleum \& Minerals, \\ Dhahran 31261, Saudi Arabia; hammad.khalid@kfupm.edu.sa \\ 3 Department of Infrastructure Safety Research, Korea Institute of Civil Engineering and Building Technology, \\ Ilsan 10223, Korea; nklee@kict.re.kr \\ * Correspondence: haengki@kaist.ac.kr; Tel.: +82-42-350-3623; Fax: +82-42-350-3610
}

check for updates

Citation: Ryu, G.U.; Khalid, H.R.; Lee, N.; Wang, Z.; Lee, H.K. The Effects of $\mathrm{NaOH}$ Concentration on the Hydrothermal Synthesis of a Hydroxyapatite-Zeolite Composite Using Blast Furnace Slag. Minerals 2021, 11, 21. https://dx.doi.org/ $10.3390 / \min 11010021$

Received: 10 December 2020 Accepted: 24 December 2020 Published: 27 December 2020

Publisher's Note: MDPI stays neutral with regard to jurisdictional claims in published maps and institutional affiliations.

Copyright: () 2020 by the authors. Licensee MDPI, Basel, Switzerland. This article is an open access article distributed under the terms and conditions of the Creative Commons Attribution (CC BY) license (https: / / creativecommons.org/ licenses/by/4.0/).

\begin{abstract}
This study investigated the effect of $\mathrm{NaOH}$ concentration on the assemblage, crystallinity, and dimension of crystalline phases in hydroxyapatite-zeolite composites made with blast furnace slag. X-ray diffraction (XRD), Fourier transform infrared (FT-IR) spectroscopy measurement, scanning electron microscopy (SEM), and nitrogen adsorption-desorption tests were conducted to characterize the synthesized composites. In addition, the cesium adsorption potential of the synthesized composites was evaluated to assess the feasibility of using hydroxyapatite-zeolite composites synthesized from blast furnace slag. The composite samples using a $3 \mathrm{M} \mathrm{NaOH}$ solution showed the formations of Na-P1 and Faujasite (FAU) zeolites along with hydroxyapatite, which led to the highest adsorption capacity for cesium $(44.90 \mathrm{mg} / \mathrm{g})$.
\end{abstract}

Keywords: hydroxyapatite; hydrothermal synthesis; blast furnace slag; $\mathrm{NaOH}$ concentration; zeolite

\section{Introduction}

Zeolites, which have a chemical formula of $A_{\mathrm{m}}\left[\mathrm{Al}_{\mathrm{m}} \mathrm{Si}_{n} \mathrm{O}_{2(\mathrm{~m}+\mathrm{n})}\right] \cdot \mathrm{xH}_{2} \mathrm{O}$ (where $A$ represents alkali metals), and hydroxyapatite $\left(\mathrm{Ca}_{10}\left(\mathrm{PO}_{4}\right)_{6}(\mathrm{OH})_{2}\right)$ are widely used materials in various fields, especially in the field of environmental engineering and for medical applications [1-4]. In particular, zeolites and hydroxyapatite have been used as adsorbents for water purification because of their high ion exchangeabilities with a high specific surface area [5-9]. It is well known that zeolites have a particular affinity towards cation adsorption, because of their cation exchangeability $[10,11]$. On the other hand, the $\mathrm{Ca}^{2+}$ and $\mathrm{OH}^{-}$ions of hydroxyapatite can be replaced by the other cations and anions, respectively [6,12-16]. Many studies have removed $\mathrm{Cl}^{-}, \mathrm{F}^{-}, \mathrm{NO}_{3}{ }^{-}$, and $\mathrm{AsO}_{4}{ }^{3-}$ using this phenomenon [6,12-16]. Moreover, Ozeki and Aoki [17] reported that hydroxyapatite has a better adsorption capacity for strontium than zeolite, while zeolite has a better adsorption capacity for cesium than hydroxyapatite, meaning that zeolites and hydroxyapatite have different adsorption capacities for certain cation ions. Therefore, zeolites and hydroxyapatite can compensate for each other's drawbacks when used simultaneously.

Blast furnace slag is an industrial byproduct, rich in calcium, silicon, and aluminum components. About 400 million tons of slag are produced annually worldwide as a byproduct of the steelmaking process [18,19]. A major portion of the generated blast furnace slag is used as a supplementary cementitious material in the concrete industry in an effort to reduce environmental impacts that occur from the use of Portland cement [20-24]. Several studies have utilized blast furnace slag for the synthesis of adsorbents, yet these studies were not able to fully utilize calcium content in the blast furnace slag for increasing the adsorption performance, considering the high calcium availability in blast 
furnace slag [25-27]. It has been reported recently that zeolites and hydroxyapatites can be simultaneously synthesized from blast furnace slag under hydrothermal conditions $[8,13]$. Kuwahara et al. [1,13] synthesized zeolites and hydroxyapatite using blast furnace slag, observing the formation of these phases over time. Ryu et al. [8] investigated the effects of the reaction temperature on the hydrothermal synthesis of zeolites and hydroxyapatite using blast furnace slag. It was found that hydroxyapatite was solely synthesized under $90{ }^{\circ} \mathrm{C}$, while both zeolites and hydroxyapatite were synthesized above $90^{\circ} \mathrm{C}$ [8]. Moreover, hydroxysodalite was formed above $120^{\circ} \mathrm{C}$ at the expense of zeolites [8].

It has also been reported in literature that the initial alkalinity of the mixture also played important roles in the hydrothermal synthesis of zeolites and hydroxyapatite using fly ash and deoxycytidine diphosphate $\left(\mathrm{C}_{9} \mathrm{H}_{15} \mathrm{~N}_{3} \mathrm{O}_{10} \mathrm{P}_{2}\right)$, respectively $[28$,29]. Earlier works on the hydrothermal synthesis of hydroxyapatite reported that the high initial $\mathrm{pH}$ of the mixtures led to the formation of high crystalline hydroxyapatite with large particles of more than $20 \mu \mathrm{m}[28,30,31]$. However, previous studies revealed that the crystallinity and particle size of hydroxyapatite synthesized by the hydrothermal treatment reduced as the initial $\mathrm{pH}$ of the mixture increased beyond the proper level [32,33]. This indicates that a certain $\mathrm{pH}$ range should be used to obtain the appropriate crystallinity and particle size of hydroxyapatite [34]. The structure, morphology, and particle size distribution of the synthesized zeolites are also deeply affected by the $\mathrm{NaOH}$ concentration of the initial mixture [29].

The effects of the initial $\mathrm{NaOH}$ concentration on the synthesis of hydroxyapatite using blast furnace slag have not, to the best of our knowledge, been reported in the literature. In this study, thus, the effect of $\mathrm{NaOH}$ concentration on the assemblage, crystallinity, and dimension of crystalline phases in hydroxyapatite-zeolite composites synthesized from blast furnace slag was investigated. To characterize the synthesized composites, $\mathrm{X}$-ray diffraction (XRD), Fourier transform infrared (FT-IR) spectroscopy measurement, scanning electron microscopy (SEM), and nitrogen adsorption-desorption tests for Brunauer-EmmettTeller (BET) and Barrett-Joyner-Halenda (BJH) analyses were conducted. The cesium adsorption potential of the composite was also evaluated so as to assess the feasibility of using hydroxyapatite-zeolite composites synthesized from blast furnace slag.

\section{Experimental Program}

\subsection{Sample Perparation}

The chemical compositions of blast furnace slag (produced from Hyundai Jecheol, Dangin, Korea) measured using the X-ray fluorescence test are listed in Table 1. The composite samples were synthesized as follows: a suspension composed of $30 \mathrm{~g}$ of blast furnace slag and $200 \mathrm{~mL}$ of phosphoric acid $\left(\mathrm{H}_{3} \mathrm{PO}_{4}, 85 \%\right.$, Samchun Pure Chemical Co., Ltd., Pyeongtaek, Korea) solution was stirred at $350 \mathrm{rpm}$ for $2 \mathrm{~h}$. It should be noted that the $\mathrm{Ca} / \mathrm{P}$ molar ratio of the suspension was fixed at 1.7 , as recommended in previous works $[1,8,13,31]$. In this step, dicalcium phosphate dihydrate $\left(\mathrm{CaHPO}_{4} \cdot 2 \mathrm{H}_{2} \mathrm{O}\right)$ is synthesized [13].

$$
\mathrm{Ca}^{2+}+\mathrm{H}^{+}+\mathrm{PO}_{4}{ }^{-}+2 \mathrm{H}_{2} \mathrm{O}=\mathrm{CaHPO}_{4} \cdot 2 \mathrm{H}_{2} \mathrm{O}
$$

Subsequently, $350 \mathrm{~mL}$ of $\mathrm{NaOH}$ (97\%, Daejung Chemicals and Metals Co., Ltd., Siheung, Korea) solution with specific concentrations of $0.5,1,2,3,4$, or $5 \mathrm{M}$ were added to the suspension for the alkaline activation; thereafter, the samples were stirred at $450 \mathrm{rpm}$ for $2 \mathrm{~h}$. From this step, dicalcium phosphate dihydrate is slowly changed into hydroxyapatite [13]. The mechanism details of the formation of hydroxyapatite and zeolite from blast furnace slag can be found in Kuwahara et al. [1,13]. The samples activated with $0.5,1,2,3$, 4, or $5 \mathrm{M}$ were denoted as HZ-0.5, HZ-1, HZ-2, HZ-3, HZ-4, and HZ-5, respectively. Thus, the liquid to solid phase ratio was $550 \mathrm{~mL} / 30 \mathrm{~g}$ in this study. In this step, the $\mathrm{pH}$ of mixtures was measured to be $12.3,12.8$, and 13.1 for HZ-0.5, HZ-1, and HZ-2, respectively, while it was more than 14 for the remaining samples. The samples were poured into fully sealed Teflon bottles and then heated at $90^{\circ} \mathrm{C}$ in an oven for $48 \mathrm{~h}$. After heating, the samples were washed and filtered, followed by drying at $90^{\circ} \mathrm{C}$ overnight to obtain white powders. 
Table 1. Chemical compositions of blast furnace slag measured from X-ray fluorescence test.

\begin{tabular}{cc}
\hline Composition & Proportion (wt.\%) \\
\hline $\mathrm{CaO}$ & 67.60 \\
$\mathrm{SiO}_{2}$ & 18.20 \\
$\mathrm{Al}_{2} \mathrm{O}_{3}$ & 7.50 \\
$\mathrm{SO}_{3}$ & 3.10 \\
$\mathrm{Fe}_{2} \mathrm{O}_{3}$ & 1.00 \\
$\mathrm{TiO}_{2}$ & 0.95 \\
$\mathrm{~K}_{2} \mathrm{O}$ & 0.76 \\
$\mathrm{MnO}$ & 0.44 \\
$\mathrm{ZrO}$ & 0.08 \\
$\mathrm{CuO}$ & 0.05 \\
$\mathrm{NiO}$ & 0.04 \\
$\mathrm{SrO}$ & 0.02 \\
\hline
\end{tabular}

\subsection{Characterization}

The crystalline phases of the synthesized composite samples were characterized by XRD using a PANalytical X'Pert PRO-MPD at the Korea Basic Science Institute (Daegu, DA107). The composite samples were scanned at a $2 \theta 5-50^{\circ}$ scan range with a $0.2^{\circ} / \mathrm{min}$ scanning rate. The reference intensity ratio (RIR) method was used to estimate the possible quantities of the crystalline phases estimated by XRD patterns of the synthesized composite samples [35]. The FT-IR measurements using 6300FV and IRT5000 devices (JASCO, Tokyo, Japan) were taken in a range of $1900-450 \mathrm{~cm}^{-1}$ under a vacuum state. SEM tests using HITACHI SU5000 (Hitachi, Ltd., Tokyo, Japan) were conducted to explore the crystal morphology and the size of the synthesized composite samples. Before the SEM tests, the surfaces of the synthesized samples were coated with Pt to increase the visibility of the morphologies. Nitrogen adsorption-desorption tests were conducted using Tristar II 3020 (Micromeritics, Atlanta, GA, USA) to measure the specific surface area and the pore size distributions of the composite samples using the BET/BJH methods.

\subsection{Batch Test}

To investigate the cesium adsorption capacities of the synthesized composite samples, $200 \mathrm{~mL}$ of $0.01 \mathrm{M} \mathrm{CsCl}$ solution, approximately equal to $1329 \mathrm{ppm}$ for $\mathrm{Cs}^{+}$, was prepared for each synthesized composite sample. It should be noted that the concentration of $\mathrm{Cs}^{+}$ for the batch test was referenced from Ozeki and Aoki [17], in which the $\mathrm{Cs}^{+}$adsorption experiments were conducted using zeolite and hydroxyapatite. Before the batch test, the synthesized samples were powdered to pass through a $64 \mu \mathrm{m}$ sieve. Next, $2 \mathrm{~g}$ of the sieved composite samples were added into the $\mathrm{CsCl}$ solution and were shaken at $120 \mathrm{rpm}$ until the extraction of the solutions. The batch composite samples were taken at 1, 3, 10, 30, and $60 \mathrm{~min}$, and were immediately filtered using a $2 \mu \mathrm{m}$ syringe filter. The residual $\mathrm{Cs}^{+}$ concentration taken from the batch composite sample was measured using an inductively coupled plasma mass spectrometer (ICP-MS, Agilent ICP-MS 7700S, Agilent, Santa Clara, CA, USA).

\section{Crystallin Characteristics and Microstructures of the Composites \\ 3.1. Crystalline Characteristics}

The XRD patterns of the raw slag and the synthesized composite samples are shown in Figure 1 . The presence of calcite $\left(\mathrm{CaCO}_{3} ; \mathrm{PDF} \#\right.$ 00-005-0586), portlandite $\left(\mathrm{Ca}(\mathrm{OH})_{2} ; \mathrm{PDF} \#\right.$ 00-037-1496), and anhydrite $\left(\mathrm{CaCO}_{4}\right.$; PDF\# 01-072-0916) were detected in the XRD pattern of the raw slag, along with an amorphous feature. The HZ-0.5, HZ-1, and HZ-2 samples solely showed peaks corresponding to the hydroxyapatite $\left(\mathrm{Ca}_{10}\left(\mathrm{PO}_{4}\right)_{6}(\mathrm{OH})_{2}, \mathrm{PDF} \#\right.$ 01-0740565) phase. On the other hand, the HZ-3 sample contained hydroxyapatite, Na-P1 zeolite (typically referred to as $\mathrm{Na}_{6} \mathrm{Al}_{6} \mathrm{Si}_{10} \mathrm{O}_{32} \cdot 12 \mathrm{H}_{2} \mathrm{O}$ PDF\# 01-071-0962), and faujasite (FAU) zeolite (typically referred to as $\mathrm{Na}_{56} \mathrm{Al}_{56} \mathrm{Si}_{136} \mathrm{O}_{384}$ PDF\# 00-012-0246) phases. The XRD pattern of the HZ-4 and HZ-5 samples showed hydroxyapatite, Na-P1 zeolite, and hydroxysodalite 
(generally denoted in $\mathrm{Na}_{8} \mathrm{Al}_{6} \mathrm{Si}_{6} \mathrm{O}_{24}$ PDF\# 00-042-0216) phases. This indicates that zeolite phases cannot be produced when the concentration of the $\mathrm{NaOH}$ solution is lower than $3 \mathrm{M}$. The initial pH of the HZ-0.5, HZ-1, and HZ-2 samples were 12.3, 12.8, and 13.1, respectively, whereas the initial $\mathrm{pH}$ of the HZ-3 sample was beyond 14. It should be noted that the possible measurement range of the $\mathrm{pH}$ level was limited to 14 in this experiment. On the other hand, hydroxysodalite, which is a zeolite-like material but has a lower specific surface area than that of zeolites, was formed in the HZ-4 and HZ-5 samples [8,25].

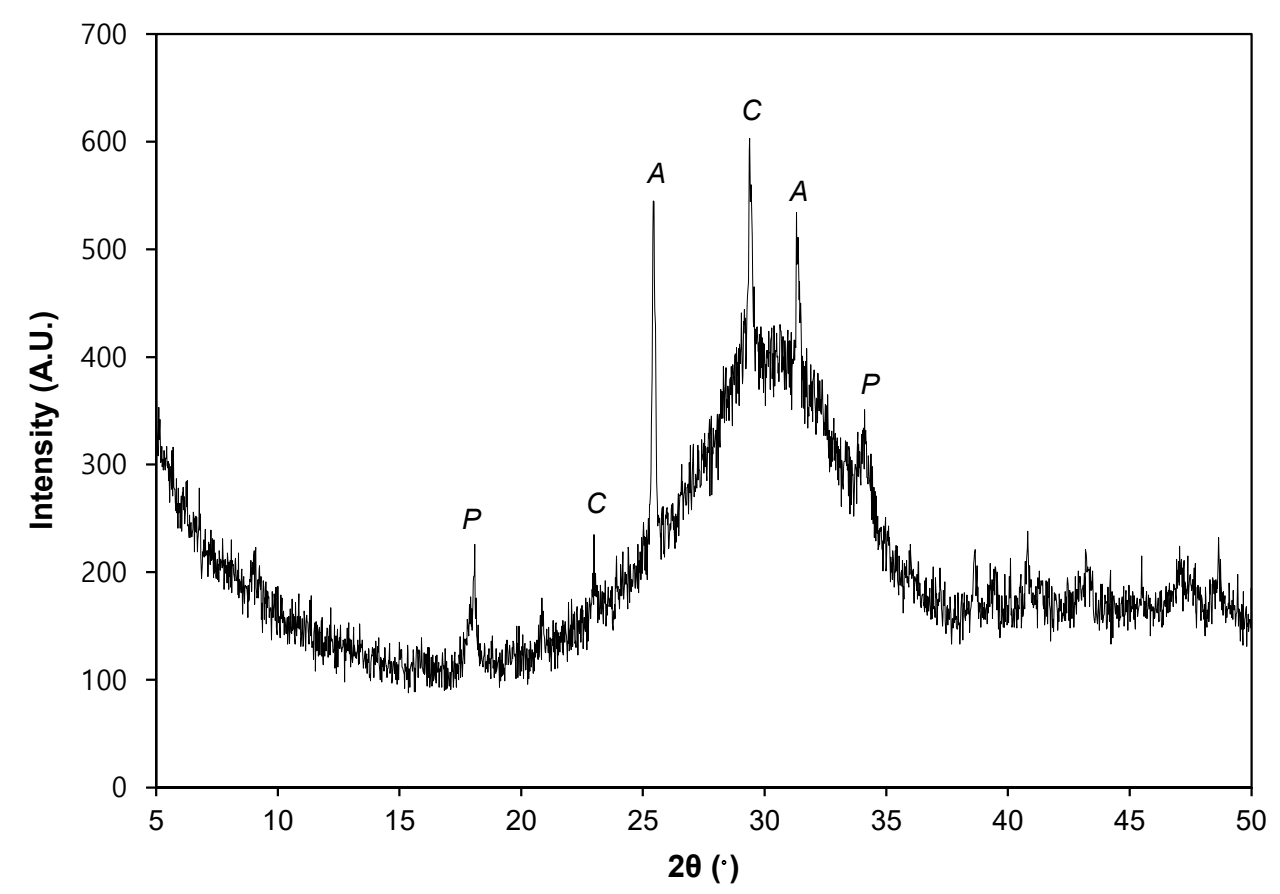

(a)

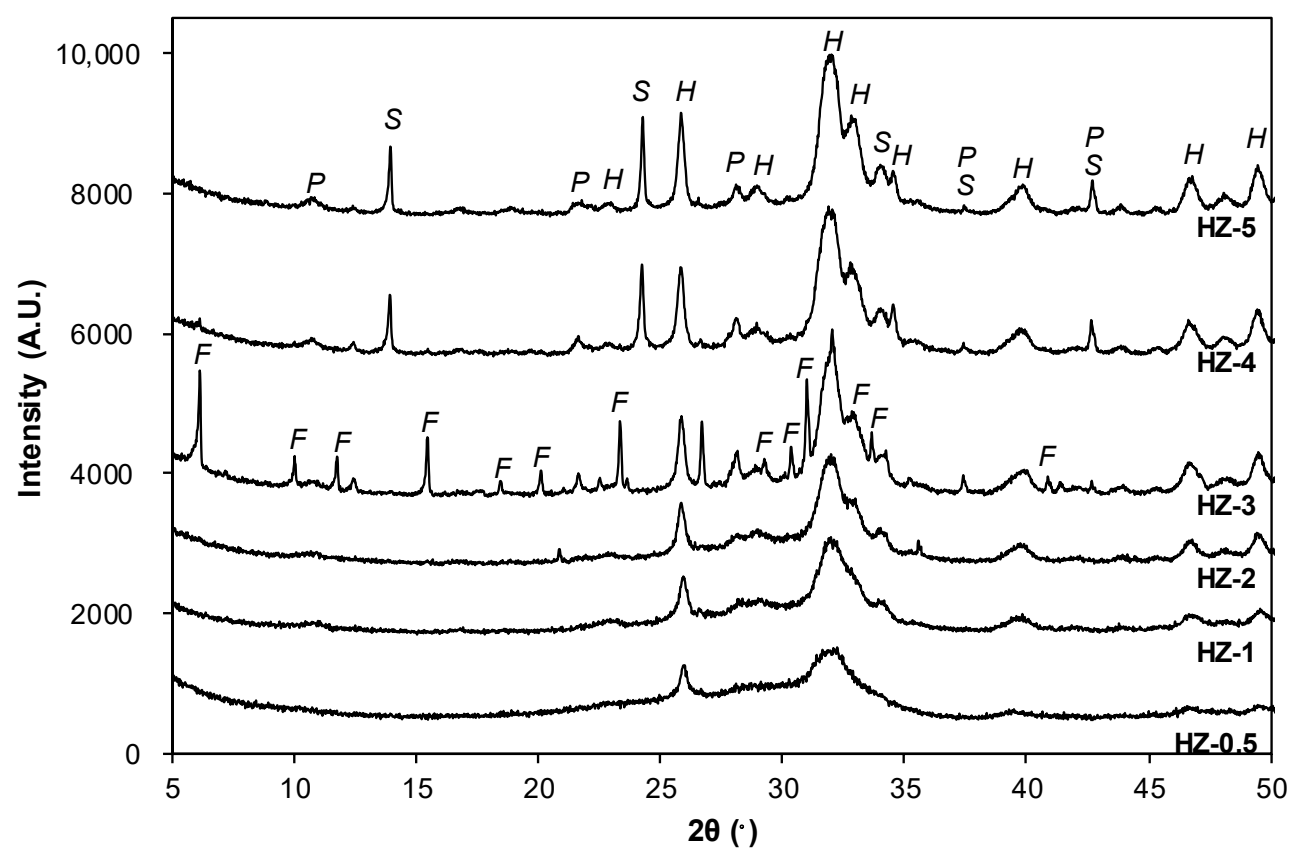

(b)

Figure 1. The XRD patterns of the (a) raw slag and (b) synthesized composite samples ( $C$-calcite; $\mathrm{P}-$ portlandite; A-anhydrite; H-hydroxyapatite; F—faujasite (FAU) zeolite; P-Na-P1 zeolite; S—hydroxysodalite). 
The crystallinities and quantitative contents of the phases of the synthesized composite samples as measured from the XRD patterns in the RIR method are listed in Table 2. It is clear that the crystallinity of the synthesized composite samples was influenced by the $\mathrm{NaOH}$ concentration of the initial mixture. The crystallinity increased significantly as the molarity of $\mathrm{NaOH}$ increased from 0.5 to $3 \mathrm{M}$. However, a further increase in the $\mathrm{NaOH}$ molarity did not have a significant effect on the crystallinity. The measured hydroxyapatite contents of the HZ-0.5, HZ-1, HZ-2, HZ-3, HZ-4, and HZ-5 samples were 25, 40, 55, 54, 48, and $52 \mathrm{wt} . \%$, respectively. The hydroxyapatite content tended to be increased significantly as the concentration of the $\mathrm{NaOH}$ solution increased from 0.5 to $2 \mathrm{M}$. However, a further increase in the $\mathrm{NaOH}$ molarity did not promote the formation of hydroxyapatite. Zeolite phases were produced in the composite samples made with a $\mathrm{NaOH}$ solution possessing a concentration higher than $2 \mathrm{M}$. The $1 \mathrm{wt}$.\% of FAU zeolite was produced only in the HZ-3 sample. The amount of Na-P1 zeolite, which has a higher adsorption capacity than FAU zeolite and hydroxysodalite, was approximately $9 \mathrm{wt} . \%$ in the HZ-3 sample. On the other hand, the HZ-4 and HZ-5 samples contained $13 \mathrm{wt} . \%$ and $10 \mathrm{wt} . \%$ of hydroxysodalite, respectively, whereas the hydroxyapatite and Na-P1 zeolite contents in these samples decreased compared with those of the HZ-3 sample. It is surmised that a further increase in the $\mathrm{NaOH}$ solution concentration decreases the crystallization of the Na-P1 zeolite. This result is similar to previous studies [36-38]. The difference in the formed crystalline phases for each composite sample is possibly associated with the $\mathrm{Na}^{+}$and $\mathrm{OH}^{-}$concentration in the initial sample mixture and the solubility of $\mathrm{Si}$ and $\mathrm{Al}$ in different alkaline conditions. $\mathrm{Si}$ and $\mathrm{Al}$ are known to be soluble in alkali conditions [6,17,28,30,33]. According to Wang et al. [29], the change in the amount of dissolved $\mathrm{Al}$ with an increasing $\mathrm{NaOH}$ concentration was negligibly small compared with the changes in the amount of dissolved Si. The amount of dissolved $\mathrm{Si}$ increased considerably with increasing the $\mathrm{NaOH}$ concentration [29]. Zeolite formation usually needs a high Si content than Al [29,39]. This phenomenon led to satisfying the $\mathrm{SiO}_{2} / \mathrm{Al}_{2} \mathrm{O}_{3}$ molar ratio required for zeolite formation, by increasing the $\mathrm{NaOH}$ concentration. Moreover, The formation of hydroxysodalite requires a higher $\mathrm{SiO}_{2} / \mathrm{Al}_{2} \mathrm{O}_{3}$ molar ratio (2- $\infty$ ) than that of the FAU (2-3) and Na-P1 zeolites (2-9) [40], hence it was formed only in samples HZ-4 and HZ-5.

Table 2. Crystallinities and quantitative contents of the phases of the synthesized composite samples measured from XRD patterns using the reference intensity ratio (RIR) method.

\begin{tabular}{cccc}
\hline Sample ID & Crystallinity (\%) & Phase & $\begin{array}{c}\text { Quantitative } \\
\text { Content (wt.\%) }\end{array}$ \\
\hline HZ-0.5 & 25 & Hydroxyapatite & 25 \\
\hline HZ-1 & 40 & Hydroxyapatite & 40 \\
\hline HZ-2 & 55 & Hydroxyapatite & 55 \\
\hline \multirow{2}{*}{ HZ-3 } & \multirow{2}{*}{66} & Hydroxyapatite & 54 \\
& & Na-P1 zeolite & 9 \\
& \multirow{2}{*}{67} & FAU type zeolite & 1 \\
\hline & & Hydroxyapatite & 48 \\
& & Na-P1 zeolite & 7 \\
& & Hydroxysodalite & 13 \\
\hline & \multirow{2}{*}{67} & Hydroxyapatite & 52 \\
& & Na-P1 zeolite & 5 \\
& & Hydroxysodalite & 10 \\
\hline
\end{tabular}

The FT-IR spectra of the composite samples are shown in Figure 2. Most of the adsorption peaks of the $\mathrm{PO}_{4}{ }^{3-}$ groups are overlapped with those of the silica groups $(466,963,1037$, and $1093 \mathrm{~cm}^{-1}$ ) [1], whereas the peaks at 566 and $603 \mathrm{~cm}^{-1}$ solely denote $\mathrm{PO}_{4}{ }^{3-}$ groups in hydroxyapatite [1]. The 747-732 $\mathrm{cm}^{-1}$ peak reveals the formation of zeolite phases [1]. The peaks at 1417 and $1467 \mathrm{~cm}^{-1}$ represent $\mathrm{CO}_{3}{ }^{2-}$ groups, which are usually detected from 
hydroxyapatite synthesized in the air, because $\mathrm{CO}_{3}{ }^{2-}$ can partially replace $\mathrm{PO}_{4}{ }^{3-}$ for the synthesis of hydroxyapatite [1,41,42]. Although the HZ-2, HZ-3, HZ-4, and HZ-5 samples had these peaks, the HZ-0.5 and HZ-1 samples did not have them. This might be because the amount of the synthesized hydroxyapatite in these samples was low. In samples HZ-2, HZ-3, $\mathrm{HZ}-4$, and $\mathrm{HZ}-5, \mathrm{CO}_{3}{ }^{2-}$ was used to synthesize hydroxyapatite. Alternatively, $\mathrm{PO}_{4}{ }^{3-}$ would be sufficient to synthesize the hydroxyapatite in the HZ-0.5 and HZ-1 samples because of the lower amounts of synthesized hydroxyapatite $(\leq 40 \%)$.

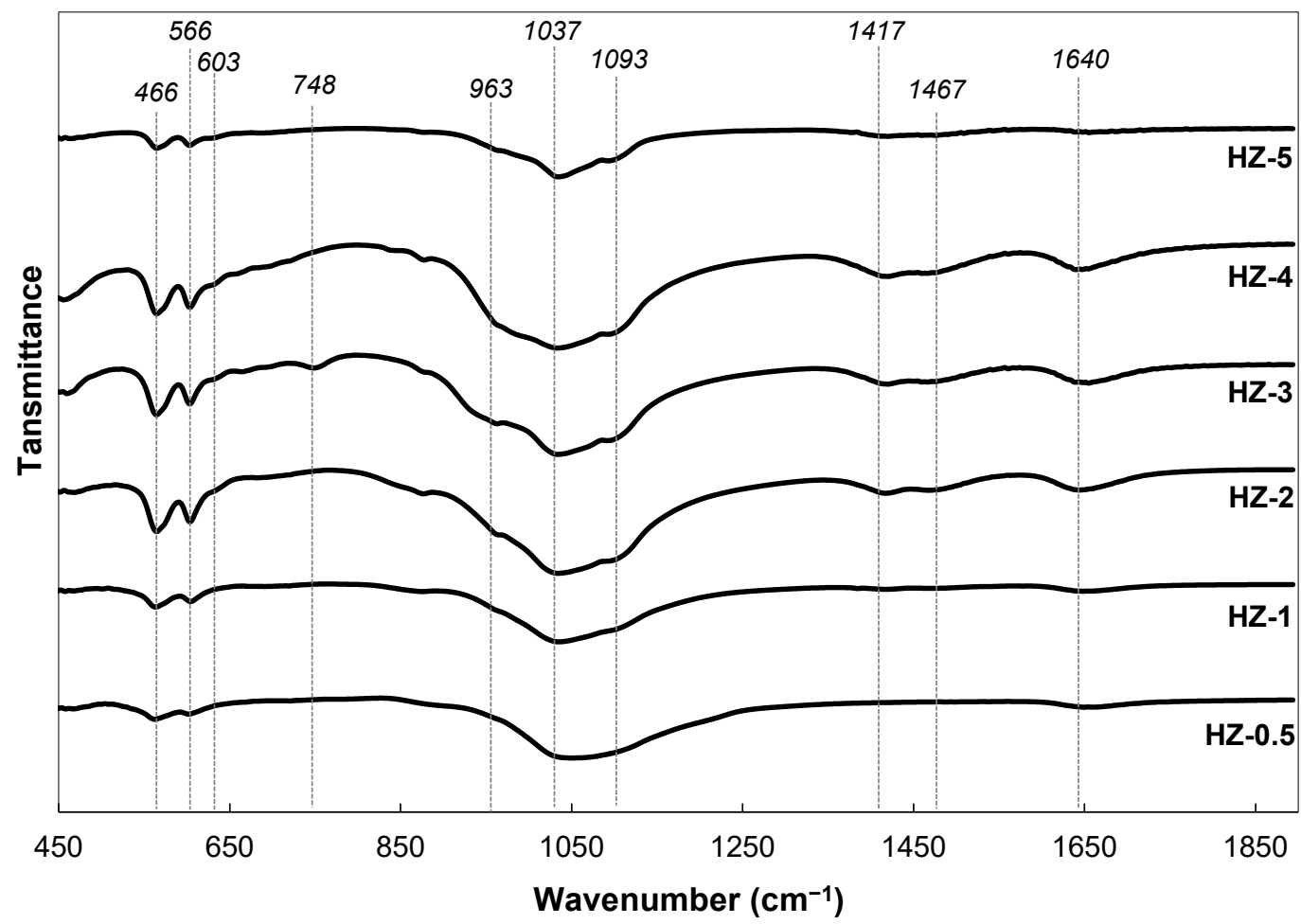

Figure 2. The FT-IR spectra of the synthesized composite samples.

\subsection{Morphology and Particle Size}

The SEM images of hydroxyapatite (captured from the HZ-5 sample), FAU zeolite (captured from the HZ-3 sample), Na-P1 zeolite (captured from the HZ-5 sample), and hydroxysodalite (captured from the HZ-5 sample) are shown in Figure 3. The SEM images of hydroxyapatite, Na-P1 zeolite, and hydroxysodalite were captured from the HZ-5 sample, as the HZ-5 sample had the highest crystallinity among the samples. On the other hand, the SEM image of the FAU zeolite was captured from the HZ-3 sample, as only the HZ-3 sample had it. The hydroxyapatite crystals in the HZ-5 sample (Figure 3a) resemble bundles of needles [43]. The spherical-shaped FAU zeolite crystals in the HZ-3 sample (Figure 3b) had a diameter of approximately $90 \mu \mathrm{m}$, with a hierarchical pore system and rectangle shape [44]. The diamond-like Na-P1 crystals with a red circle in Figure 3, approximately $18 \mu \mathrm{m}$ in size, were also detected in the HZ-5 sample (Figure 3c) [27]. In Figure $3 \mathrm{~d}$, hydroxysodalite crystals with an approximately $90 \mu \mathrm{m}$ diameter and rectangle shape are shown [45]. 

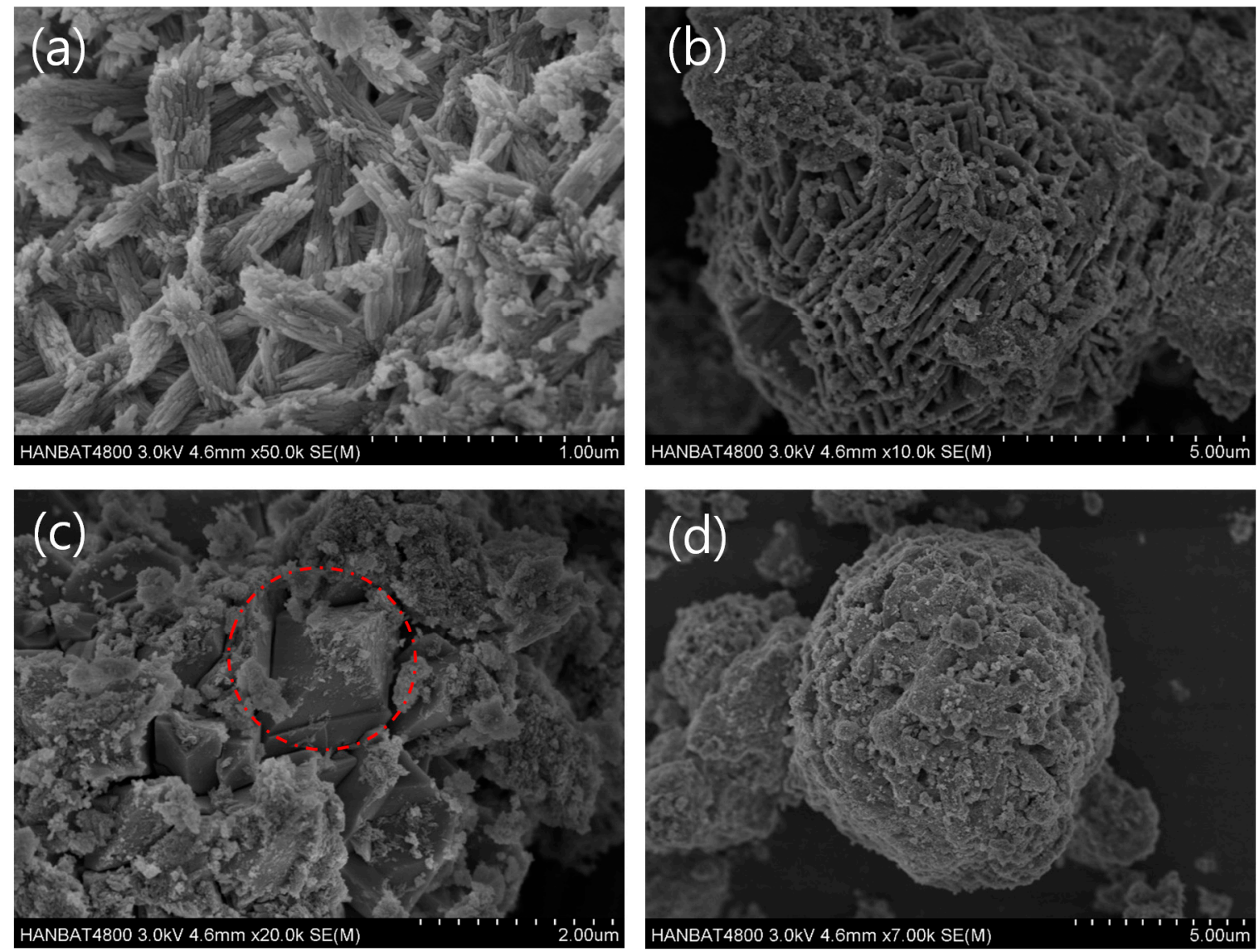

Figure 3. SEM images of (a) hydroxyapatite (obtained from HZ-5), (b) FAU zeolite (obtained from HZ-3), (c) Na-P1 zeolite (obtained from HZ-5), and (d) hydroxysodalite (obtained from HZ-5).

The SEM images of the hydroxyapatite crystalline with needle-like shapes captured from the HZ-0.5, HZ-2, HZ-3, and HZ-5 samples are shown in Figure 4. The hydroxyapatite crystals in the composite samples were denoted by red circles in Figure 4. Figure 4 indicates the effect of $\mathrm{NaOH}$ concentration on the synthesized hydroxyapatite crystals. As the initial concentration of $\mathrm{NaOH}$ increased, it was found that the size and crystallinity of the hydroxyapatite crystals increased. The hydroxyapatite crystals with a needle-like shape in the HZ-0.5 sample were not clear enough to measure the crystal sizes, as the crystals were too small and could not easily be identified. In addition, the sizes of hydroxyapatite crystals in the HZ-2 sample were longer and thicker than that of the HZ-0.5 sample, but the size was confirmed to be up to a length of approximately $1 \mu \mathrm{m}$. On the other hand, the crystals of the HZ-3 sample were identified as needle-like shaped hydroxyapatite, and the length ranged from 1 to $3 \mu \mathrm{m}$. It was confirmed that the HZ-5 sample had well-developed hydroxyapatite, which could be easily identified from the other crystals, because of their length of $2-7 \mu \mathrm{m}$ and the bundle of needle shapes.

Nevertheless, as the concentration of the alkali activator increased, and the aggregations of the hydroxyapatite crystals intensified. As reported by Hansen et al. [46], it was found that as the $\mathrm{pH}$ of the initial mixture increased, the aggregation of the synthesized hydroxyapatite crystals increased, which resulted in a decrease in both the specific surface area and adsorption capacity [47]. This phenomenon could be as a result of the surface energy of hydroxyapatite crystals [46,48]. The higher alkaline condition led to a higher surface energy of hydroxyapatite crystals, and it led to the aggregation of hydroxyapatite crystals [46,49]. 

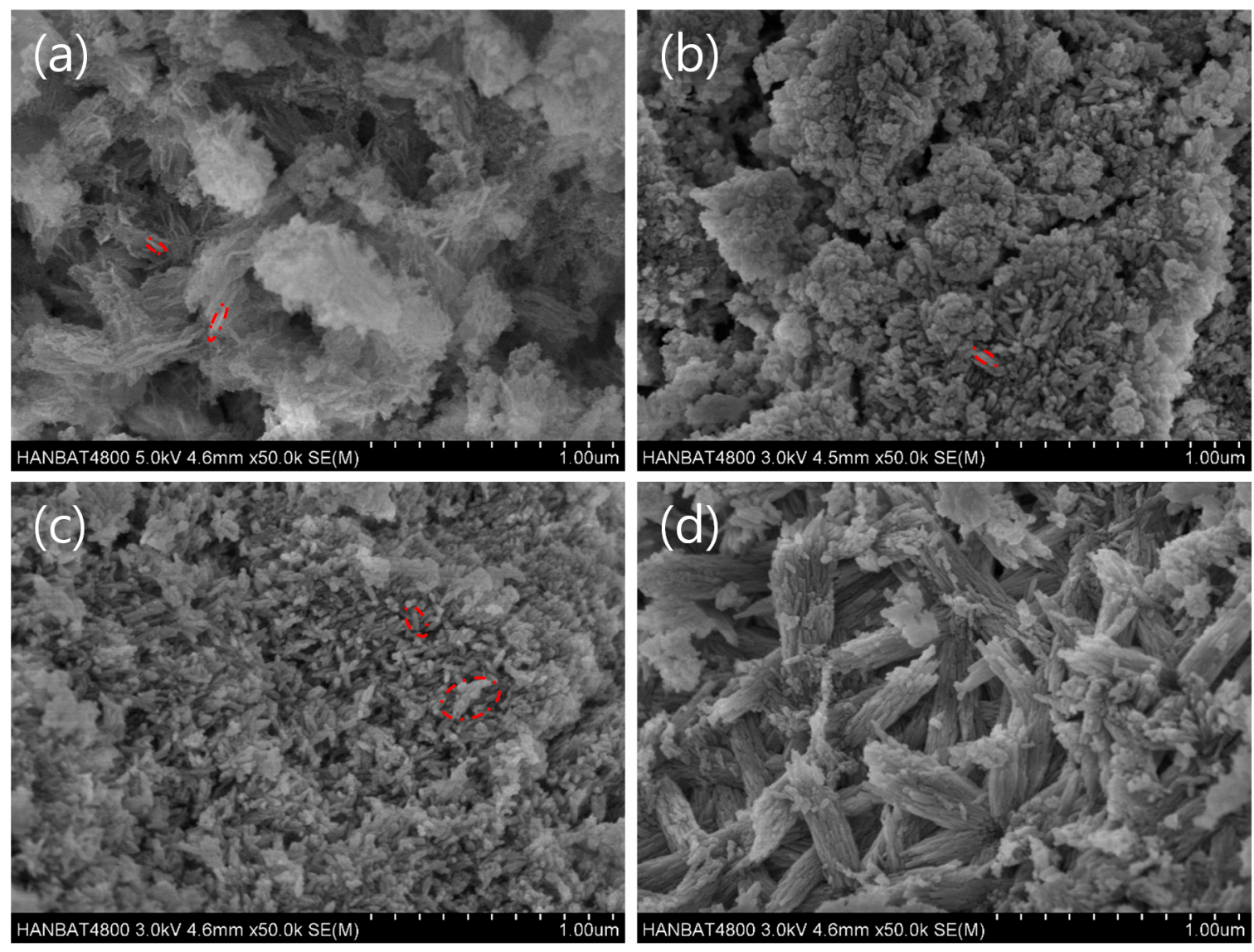

Figure 4. SEM images of hydroxyapatite crystalline obtained from (a) HZ-0.5, (b) HZ-2, (c) HZ-3, and (d) HZ-5 (red circles indicate a hydroxyapatite crystal).

\subsection{Pore Structures}

To investigate the specific surface area and pore structures of the synthesized composite samples, a BET/BJH test from the nitrogen adsorption-desorption test result was conducted. The BET/BJH test results and the pore size distributions of the synthesized composite samples measured from BJH tests are shown in Table 3 and Figure 5, respectively. Among the synthesized composite samples, the HZ-3 sample had the highest BET specific surface area $\left(143.32 \mathrm{~m}^{2} / \mathrm{g}\right)$, followed by the HZ-0.5 sample $\left(102.81 \mathrm{~m}^{2} / \mathrm{g}\right)$, while the HZ-2 sample had the lowest BET specific surface area $\left(32.12 \mathrm{~m}^{2} / \mathrm{g}\right)$. An increase in $\mathrm{NaOH}$ concentration led to a decrease in the specific surface area of the synthesized composite sample for the HZ-0.5, HZ-1, and HZ-2 samples, which solely had a hydroxyapatite phase. The changes in the specific surface area of the samples were not linear, because the crystal phases were changed for each alkali condition. This is attributed to the increased aggregation of the hydroxyapatite crystals, as also indicated in the SEM images [47]. The aggregation of the hydroxyapatite crystals could result in a disconnection of the pore connection system in hydroxyapatite crystals, and this phenomenon could lead to a reduction in the specific surface area of the hydroxyapatite crystals. Because of the formation of zeolite phases (FAU and Na-P1 zeolite) with a high specific surface area [8], the HZ-3 sample had the highest specific surface area. The specific surface area of the HZ-4 sample was much lower than that of the HZ-3 sample because of the formation of hydroxysodalite, which has a lower specific surface area than that of the Na-P1 zeolite and FAU zeolite [27]. 
Table 3. BET/BJH results of the synthesized composite samples.

\begin{tabular}{|c|c|c|c|c|c|c|}
\hline Sample ID & HZ-0.5 & HZ-1 & HZ-2 & HZ-3 & HZ-4 & HZ-5 \\
\hline Specific surface area $\left(\mathrm{m}^{2} / \mathrm{g}\right)$ & 102.81 & 50.51 & 32.12 & 143.32 & 59.39 & 72.07 \\
\hline $\begin{array}{l}\text { BJH cumulative pore volume } \\
\qquad\left(\mathrm{cm}^{3} / \mathrm{g}\right)\end{array}$ & 0.32 & 0.18 & 0.18 & 0.17 & 0.14 & 0.17 \\
\hline $\begin{array}{c}\text { BJH adsorption average pore } \\
\text { diameter }(\mathrm{nm})\end{array}$ & 12.71 & 13.87 & 10.21 & 7.37 & 8.68 & 8.80 \\
\hline $\begin{array}{l}\text { BJH adsorption cumulative specific } \\
\text { surface area of pores }\left(\mathrm{m}^{2} / \mathrm{g}\right)\end{array}$ & 101.27 & 51.32 & 69.94 & 90.12 & 66.72 & 79.30 \\
\hline
\end{tabular}

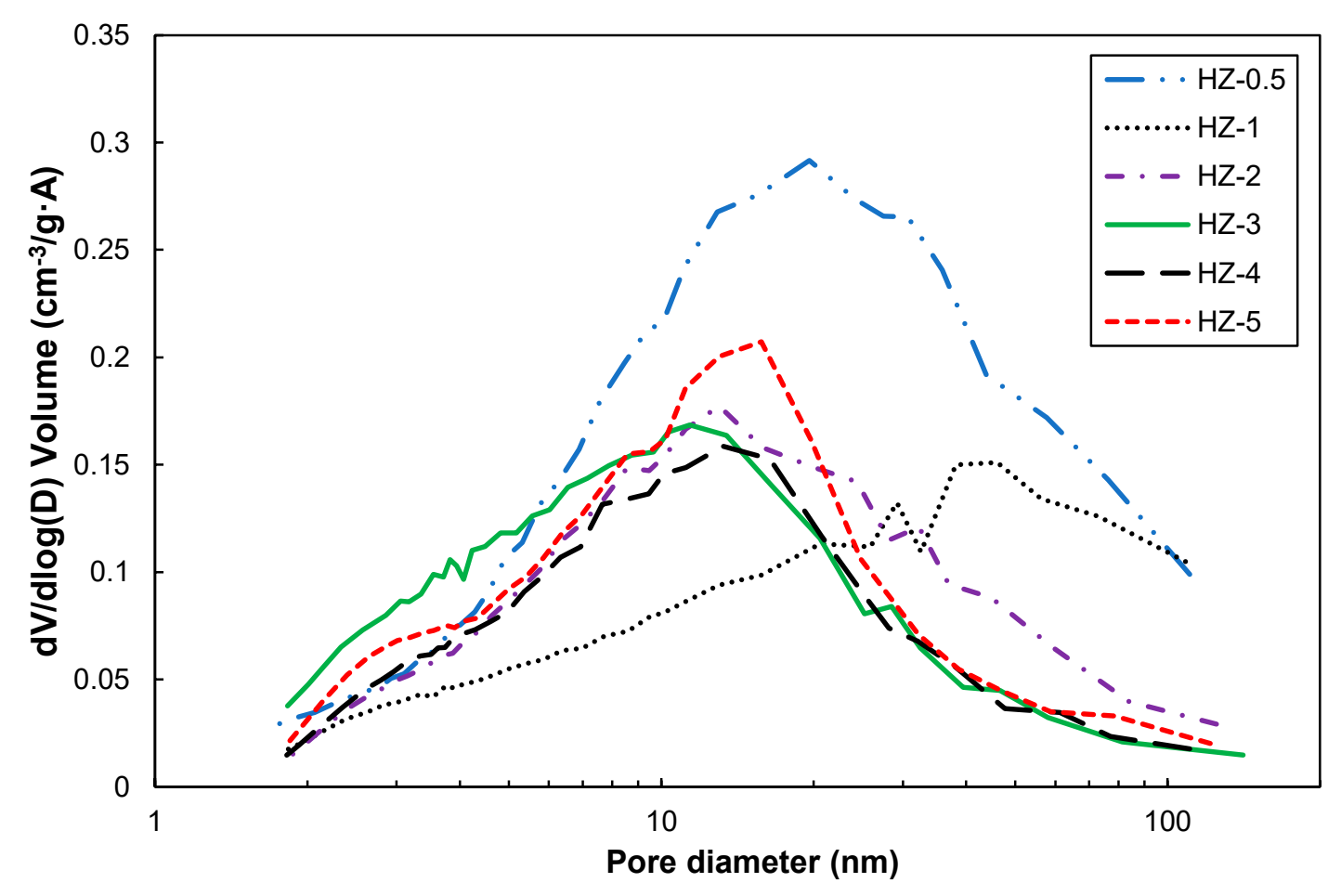

Figure 5. The pore size distributions of the synthesized composite samples measured from the BJH tests.

Khalid et al. [27] reported that the relatively small pores make the hierarchical connection system of pores in crystals, and the more relatively small pores lead to a high specific surface area in the synthesized samples. In this study, the BJH adsorption average pore diameter of the samples generally tended to be inversely proportional to the specific surface area of the samples. This means that the specific surface area of the sample increases, as the relatively small pores contain more than the large pores, because the relatively small pores establish a hierarchical connection system of pores. Although the distribution of large pores in the sample is small, in Figure 5, it can be seen that the specific surface area of the sample with many small pores is in Figure 5. Similarly, Liu et al. [47] reported that a smaller ratio of microporous area/specific surface area led to an increase in the specific area.

\section{Cesium Adsorption Capacities of the Composites}

The cesium adsorption capacities of the synthesized composite samples measured from the ICP-MS tests are shown in Figure 6. The HZ-3 sample showed the highest adsorption capacity $(44.90 \mathrm{mg} / \mathrm{g})$ because of the formation of FAU and Na-P1 zeolites, followed by the HZ-0.5 sample $(37.31 \mathrm{mg} / \mathrm{g})$. The formation of zeolites led to a higher specific surface area and ionic forces. The adsorption test results revealed that both zeolite and hydroxyapatite have a high potential for $\mathrm{Cs}^{+}$adsorption; however, it is better to use hydroxyapatite-zeolite composites compared with pure hydroxyapatite for adsorbents. Thus, it is recommended to synthesize both hydroxyapatite and zeolite from blast furnace 
slag to remove $\mathrm{Cs}^{+}$. However, HZ-4 and HZ-5 had lower adsorption capacities than that of HZ-0.5, HZ-1, and HZ-2, although they had the Na-P1 zeolite. This could be due to the intensified aggregation of hydroxyapatite crystals and the formation of hydroxysodalite.

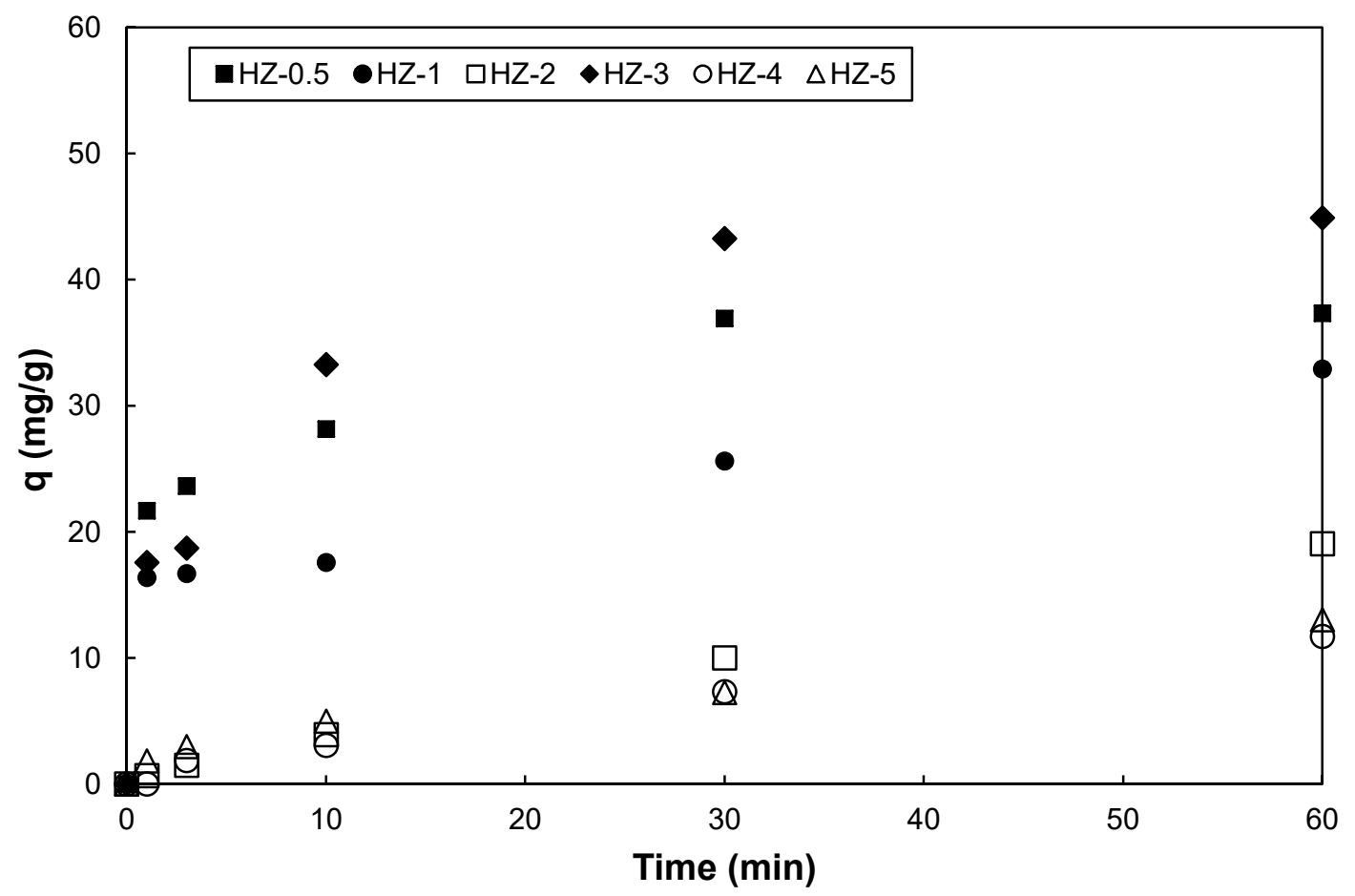

Figure 6. Cesium adsorption capacities of the synthesized composite samples measured from the ICP-MS tests.

For the samples containing hydroxyapatite solely (the HZ-0.5, -1, and -2 samples), the adsorption capacities tended to decrease as the $\mathrm{NaOH}$ concentration of the initial sample mixture increased. This is a result of the high concentration of $\mathrm{NaOH}$, leading to the aggregation of hydroxyapatite crystals. The aggregation resulted in a decrease in the specific surface area, which could prevent the diffusion of $\mathrm{Cs}^{+}$ions into the crystal (see Table 3). Thus, $\mathrm{Ca}^{2+}$ ions located deep inside the hydroxyapatite crystals might not undergo ion exchange with $\mathrm{Cs}^{+}$ions. This phenomenon ultimately led to a reduction in the adsorption capacity of the synthesized composite sample. For further insight, the adsorption capacities of the synthesized composite samples against the BET surface area are shown in Figure 7. Regarding the HZ-0.5, HZ-1, HZ-2, and HZ-3 samples, the adsorption capacity increased with the specific surface area. On the other hand, hydroxyapatite-hydroxysodalite (the HZ4 and HZ-5 samples), which was synthesized with a high concentration of alkali activator, had a relatively low adsorption capacity $(11.72$ and $13.03 \mathrm{mg} / \mathrm{g}$ ) against the specific surface area compared with the other composite samples. This is ascribed to hydroxysodalite having a lower adsorption capacity than FAU zeolite and Na-P1 zeolite. Moreover, the intensified aggregation of hydroxyapatite crystals possibly led to the decreased adsorption capacity of the hydroxyapatite, as mentioned above [47,50].

Overall, increasing the alkali activator concentration augmented the aggregation of hydroxyapatite crystals, thereby reducing their specific surface area [46,47]. On the other hand, the HZ-3 sample showed the highest adsorption capacity because of the high specific surface area resulting from the formation of Na-P1 and FAU zeolite [1]. The specific surface area and adsorption capacity of the HZ-4 and HZ-5 samples were greatly decreased because of the formation of hydroxysodalite and the intensified aggregation of hydroxyapatite crystals $[47,50]$. 


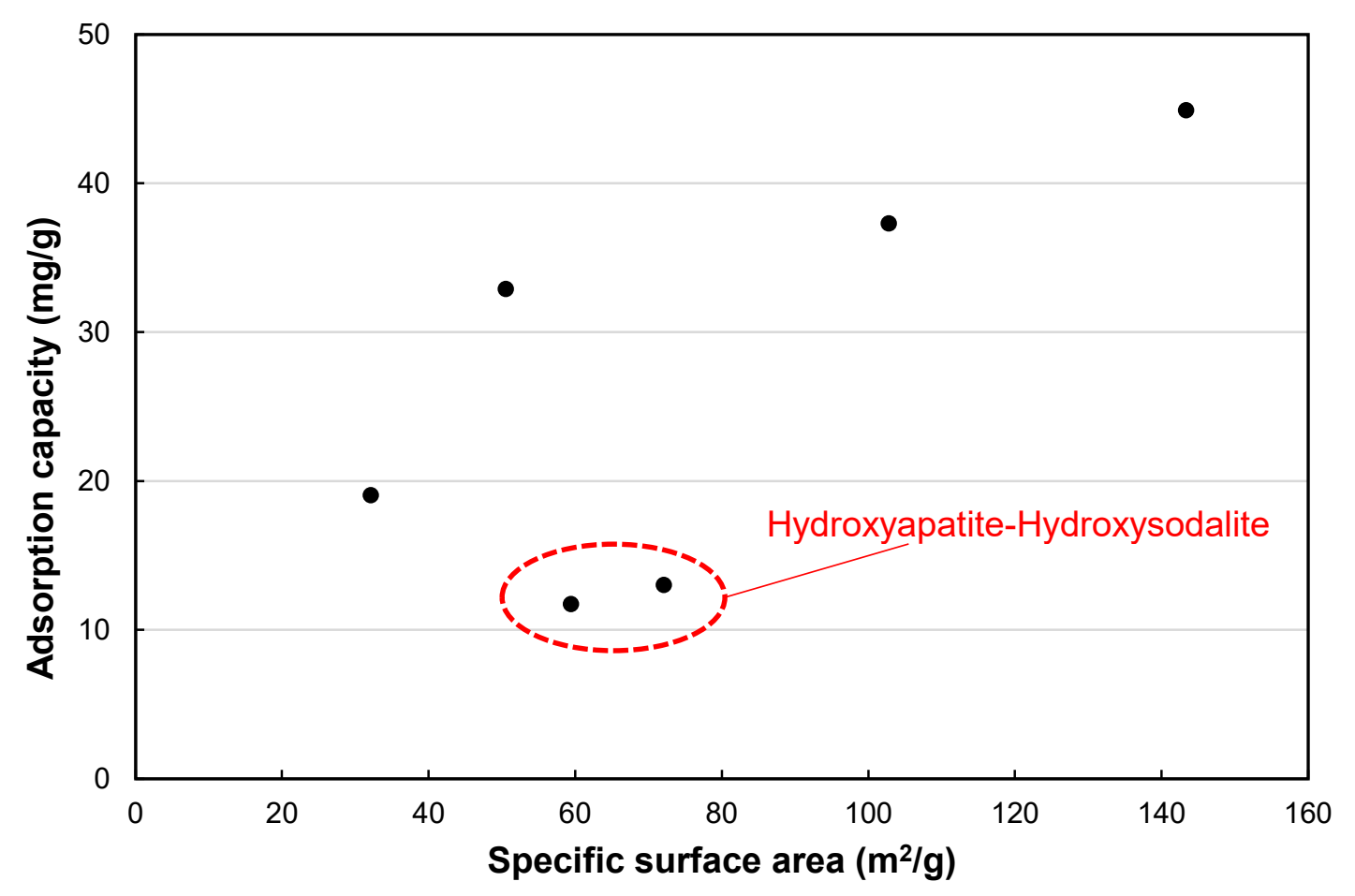

Figure 7. The adsorption capacities of the synthesized composite samples against the BET surface area.

\section{Concluding Remarks}

In this study, the effect of the $\mathrm{NaOH}$ concentration on the hydrothermal synthesis of hydroxyapatite-zeolite made with blast furnace slag was investigated. The composite samples synthesized with different concentrations of $\mathrm{NaOH}$ solutions were characterized by XRD, FT-IR, SEM, and BET/BJH analyses. The adsorption capacities of the synthesized composite samples for $\mathrm{Cs}^{+}$were investigated. The results of this study can be summarized as follows:

(1) As the $\mathrm{NaOH}$ concentration increased from 0.5 to $3 \mathrm{M}$, the overall crystallinity increased from about $25 \%$ to about $66 \%$. However, a further increase in the $\mathrm{NaOH}$ concentration did not affect the overall crystallinity. Instead, the crystalline phases and their content varied.

(2) The composite samples synthesized with a $0.5,1$, or $2 \mathrm{M} \mathrm{NaOH}$ solution contained an increasing content of the sole crystalline phase, i.e., hydroxyapatite. Nevertheless, the specific surface area and adsorption capacity of the composite samples for $\mathrm{Cs}^{+}$ decreased in these composite samples because of the aggregation of hydroxyapatite crystals as the concentration of the $\mathrm{NaOH}$ solution increased from 0.5 to $2 \mathrm{M}$.

(3) The composite sample synthesized with $3 \mathrm{M}$ of the $\mathrm{NaOH}$ solution had the highest specific area and adsorption capacity for $\mathrm{Cs}^{+}$among all of the composite samples in this study, because of the formation of Na-P1 and FAU zeolites along with hydroxyapatite.

(4) A further increase in the $\mathrm{NaOH}$ molarity (more than $4 \mathrm{M}$ ) resulted in a reduced specific surface area and adsorption capacity for $\mathrm{Cs}^{+}$because of the formation of hydroxysodalite and the intensified aggregation of hydroxyapatite.

In conclusion, the optimal concentration for the $\mathrm{NaOH}$ solution is around $3 \mathrm{M}$, at which zeolite phases can be formed, resulting in an improved adsorption capacity for the slag-based adsorbents. Research on the particle size before and after synthesis needs to be conducted in the future. 
Author Contributions: Conceptualization, H.R.K. and G.U.R.; methodology, H.R.K. and G.U.R.; validation, G.U.R.; formal analysis G.U.R. and Z.W.; investigation, G.U.R.; writing-original draft preparation, G.U.R.; writing—review and editing, G.U.R., N.L., H.R.K., Z.W. and H.K.L.; supervision, H.K.L.; project administration, H.K.L.; funding acquisition, H.K.L. All authors have read and agreed to the published version of the manuscript.

Funding: This research was supported by a grant from the National Research Foundation of Korea (NRF; 2018R1A2A1A05076894), funded by the Korean government.

Data Availability Statement: The data presented in this study are available on request from the corresponding author.

Acknowledgments: The authors acknowledge H. J. No at KBSI (Daegu) for their useful discussion and for collecting the XRD data.

Conflicts of Interest: The authors declare no conflict of interest.

\section{References}

1. Kuwahara, Y.; Ohmichi, T.; Kamegawa, T.; Mori, K.; Yamashita, H. A novel synthetic route to hydroxyapatite-zeolite composite material from steel slag: Investigation of synthesis mechanism and evaluation of physicochemical properties. J. Mater. Chem. 2009, 19, 7263-7272. [CrossRef]

2. Saito, M.; Maruoka, A.; Mori, T.; Sugano, N.; Hino, K. Experimental studies on a new bioactive bone cement: Hydroxyapatite composite resin. Biomaterials 1994, 15, 156-160. [CrossRef]

3. He, P.; Ding, J.; Qin, Z.; Tang, L.; Haw, K.G.; Zhang, Y.; Fang, Q.; Qiu, S.; Valtchev, V. Binder-free preparation of ZSM-5@silica beads and their use for organic pollutant removal. Inorg. Chem. Front. 2020, 7, 2080-2088. [CrossRef]

4. Wang, Y.; Jia, H.; Chen, P.; Fang, X.; Du, T. Synthesis of La and Ce modified X zeolite from rice husk ash for carbon dioxide capture. J. Mater. Res. Technol. 2020, 9, 4368-4378. [CrossRef]

5. Roy, D.M.; Linnehan, S.K. Hydroxyapatite formed from coral skeletal carbonate by hydrothermal exchange. Nature 1974, $247,220$. [CrossRef] [PubMed]

6. He, J.; Zhang, K.; Wu, S.; Cai, X.; Chen, K.; Li, Y.; Sun, B.; Jia, Y.; Meng, F.; Jin, Z.; et al. Performance of novel hydroxyapatite nanowires in treatment of fluoride contaminated water. J. Hazard. Mater. 2016, 303, 119-130. [CrossRef] [PubMed]

7. Kendrick, E.; Dann, S. Synthesis, properties and structure of ion exchanged hydrosodalite. J. Solid State Chem. 2004, 177, 1513-1519. [CrossRef]

8. Ryu, G.U.; Kim, G.M.; Khalid, H.R.; Lee, H.K. The effects of temperature on the hydrothermal synthesis of hydroxyapatite-zeolite using blast furnace slag. Materials 2019, 12, 2131. [CrossRef]

9. Yang, C.; Zhang, W.; Wang, J.; Li, S.; Liu, X.; Dou, L.; Yue, T.; Sun, J.; Wang, J. Nanostructured morphology control and phase transition of zeolitic imidazolate frameworks as an ultra-high performance adsorbent for water purification. Inorg. Chem. Front. 2019, 6, 2667-2674. [CrossRef]

10. Gómez del Río, J.A.; Morando, P.J.; Cicerone, D.S. Natural materials for treatment of industrial effluents: Comparative study of the retention of $\mathrm{Cd}, \mathrm{Zn}$ and Co by calcite and hydroxyapatite. Part I: Batch experiments. J. Environ. Manag. 2004, 71, 169-177. [CrossRef]

11. Lee, N.K.; Khalid, H.R.; Lee, H.K. Adsorption characteristics of cesium onto mesoporous geopolymers containing nano-crystalline zeolites. Microporous Mesoporous Mater. 2017, 242, 238-244. [CrossRef]

12. Yanagisawa, K.; Rendon-Angeles, J.C.; Ishizawa, N.; Oishi, S. Topotaxial replacement of chlorapatite by hydroxyapatite during hydrothermal ion exchange. Am. Mineral. 1999, 84, 1861-1869. [CrossRef]

13. Kuwahara, Y.; Ohmichi, T.; Kamegawa, T.; Mori, K.; Yamashita, H. Synthesis of Hydroxyapatite-Zeolite Composite Material from Disposed Steel Slag and Investigation of Its Structural and Physicochemical Characteristics. Chem. Lett. 2009, 38, 626-627. [CrossRef]

14. Islam, M.; Chandra Mishra, P.; Patel, R. Physicochemical characterization of hydroxyapatite and its application towards removal of nitrate from water. J. Environ. Manag. 2010, 91, 1883-1891. [CrossRef] [PubMed]

15. Islam, M.; Mishra, P.C.; Patel, R. Arsenate removal from aqueous solution by cellulose-carbonated hydroxyapatite nanocomposites. J. Hazard. Mater. 2011, 189, 755-763. [CrossRef]

16. Chen, L.; Zhang, K.S.; He, J.Y.; Xu, W.H.; Huang, X.J.; Liu, J.H. Enhanced fluoride removal from water by sulfate-doped hydroxyapatite hierarchical hollow microspheres. Chem. Eng. J. 2016, 285, 616-624. [CrossRef]

17. Ozeki, K.; Aoki, H. Evaluation of the adsorptive behavior of cesium and strontium on hydroxyapatite and zeolite for decontamination of radioactive substances. Bio-Med Mater. Eng. 2016, 27, 227-236. [CrossRef]

18. Pan, S.Y.; Chung, T.C.; Ho, C.C.; Hou, C.J.; Chen, Y.H.; Chiang, P.C. $\mathrm{CO}_{2}$ Mineralization and Utilization using Steel Slag for Establishing a Waste-to-Resource Supply Chain. Sci. Rep. 2017, 7, 17227. [CrossRef]

19. Motz, H.; Geiseler, J. Products of steel slags an opportunity to save natural resources. Waste Manag. 2001, 21, 285-293. [CrossRef]

20. Kim, G.M.; Khalid, H.R.; Park, S.M.; Lee, H.K. Flow Property of Alkali-Activated Slag with Modified Precursor. ACI Mater. J. 2017, 114, 867-876. [CrossRef] 
21. Kim, G.M.; Khalid, H.R.; Kim, H.J.; Lee, H.K. Alkali activated slag pastes with surface-modified blast furnace slag. Cem. Concr. Compos. 2017, 76, 39-47. [CrossRef]

22. Lee, N.K.; Kim, E.M.; Lee, H.K. Mechanical properties and setting characteristics of geopolymer mortar using styrene-butadiene (SB) latex. Constr. Build. Mater. 2016, 113, 264-272. [CrossRef]

23. Jang, J.G.; Park, S.M.; Lee, H.K. Physical barrier effect of geopolymeric waste form on diffusivity of cesium and strontium. J. Hazard. Mater. 2016, 318, 339-346. [CrossRef] [PubMed]

24. Jiang, L.; Li, C.; Wang, C.; Xu, N.; Chu, H. Utilization of flue gas desulfurization gypsum as an activation agent for high-volume slag concrete. J. Clean. Prod. 2018, 205, 589-598. [CrossRef]

25. Khalid, H.R.; Lee, N.K.; Choudhry, I.; Wang, Z.; Lee, H.K. Evolution of zeolite crystals in geopolymer-supported zeolites: Effects of composition of starting materials. Mater. Lett. 2019, 239, 33-36. [CrossRef]

26. Lee, N.K.; Khalid, H.R.; Lee, H.K. Synthesis of mesoporous geopolymers containing zeolite phases by a hydrothermal treatment. Microporous Mesoporous Mater. 2016, 229, 22-30. [CrossRef]

27. Khalid, H.R.; Lee, N.K.; Park, S.M.; Abbas, N.; Lee, H.K. Synthesis of geopolymer-supported zeolites via robust one-step method and their adsorption potential. J. Hazard. Mater. 2018, 353, 522-533. [CrossRef]

28. Liu, J.; Ye, X.; Wang, H.; Zhu, M.; Wang, B.; Yan, H. The influence of $\mathrm{pH}$ and temperature on the morphology of hydroxyapatite synthesized by hydrothermal method. Ceram. Int. 2003, 29, 629-633. [CrossRef]

29. Wang, C.F.; Li, J.S.; Wang, L.J.; Sun, X.Y. Influence of $\mathrm{NaOH}$ concentrations on synthesis of pure-form zeolite A from fly ash using two-stage method. J. Hazard. Mater. 2008, 155, 58-64. [CrossRef]

30. Zhu, R.; Yu, R.; Yao, J.; Wang, D.; Ke, J. Morphology control of hydroxyapatite through hydrothermal process. J. Alloy. Compd. 2008, 457, 555-559. [CrossRef]

31. Sun, Y.; Guo, G.; Tao, D.; Wang, Z. Reverse microemulsion-directed synthesis of hydroxyapatite nanoparticles under hydrothermal conditions. J. Phys. Chem. Solids 2007, 68, 373-377. [CrossRef]

32. Zhang, H.; Darvell, B.W. Morphology and structural characteristics of hydroxyapatite whiskers: Effect of the initial Ca concentration, Ca/P ratio and pH. Acta Biomater. 2011, 7, 2960-2968. [CrossRef] [PubMed]

33. Zhang, C.; Yang, J.; Quan, Z.; Yang, P.; Li, C.; Hou, Z.; Lin, J. Hydroxyapatite nano- and microcrystals with multiform morphologies: Controllable synthesis and luminescence properties. Cryst. Growth Des. 2009, 9, 2725-2733. [CrossRef]

34. Al-Qasas, N.S.; Rohani, S. Synthesis of pure hydroxyapatite and the effect of synthesis conditions on its yield, crystallinity, morphology and mean particle size. Sep. Sci. Technol. 2005, 40. [CrossRef]

35. Jenkins, R.; Snynder, R.L. Introduction to X-ray Powder Diffractometry; Wiley: New York, NY, USA, 1996.

36. Reyes, C.A.R.; Williams, C.D.; Alarcón, O.M.C. Síntesis of zeolita LTA Frim thermally treated kaolinite. Rev. Fac. De Ing. 2010, 53, 30-41.

37. Li, Y.; Peng, T.; Man, W.; Ju, L.; Zheng, F.; Zhang, M.; Guo, M. Hydrothermal synthesis of mixtures of NaA zeolite and sodalite from Ti-bearing electric arc furnace slag. Rsc Adv. 2016, 6, 8358-8366. [CrossRef]

38. Król, M.; Mozgawa, W.; Morawska, J.; Pichór, W. Spectroscopic investigation of hydrothermally synthesized zeolites from expanded perlite. Microporous Mesoporous Mater. 2014, 196, 216-222. [CrossRef]

39. Li, J.; Li, Y.; Zhang, L.; Zuo, Y. Composition of calcium deficient Na-containing carbonate hydroxyapatite modified with Cu(II) and Zn(II) ions. Appl. Surf. Sci. 2008, 254, 2844-2850. [CrossRef]

40. Garcia, G.; Cabrera, S.; Hedlund, J.; Mouzon, J. Selective synthesis of FAU-type zeolites. J. Cryst. Growth 2018, 489, 36-41. [CrossRef]

41. Suchanek, W.L.; Byrappa, K.; Shuk, P.; Riman, R.E.; Janas, V.F.; Tenhuisen, K.S. Mechanochemical-hydrothermal synthesis of calcium phosphate powders with coupled magnesium and carbonate substitution. J. Solid State Chem. 2004, 177, 793-799. [CrossRef]

42. Ezekiel, I.; Kasim, S.R.; Ismail, Y.M.B.; Noor, A.F.M. Nanoemulsion synthesis of carbonated hydroxyapatite nanopowders: Effect of variant CO32- / PO43- molar ratios on phase, morphology, and bioactivity. Ceram. Int. 2018, 44, 13082-13089. [CrossRef]

43. Zou, Z.; Liu, X.; Chen, L.; Lin, K.; Chang, J. Dental enamel-like hydroxyapatite transformed directly from monetite. J. Mater. Chem. 2012, 22, 22637-22641. [CrossRef]

44. Rioland, G.; Albrecht, S.; Josien, L.; Vidal, L.; Daou, T.J. The influence of the nature of organosilane surfactants and their concentration on the formation of hierarchical FAU-type zeolite nanosheets. New J. Chem. 2015, 39, 2675-2681. [CrossRef]

45. Golbad, S.; Khoshnoud, P.; Abu-Zahra, N. Hydrothermal synthesis of hydroxy sodalite from fly ash for the removal of lead ions from water. Int. J. Environ. Sci. Technol. 2017, 14, 135-142. [CrossRef]

46. Hansen, N.M.; Felix, R.; Bisaz, S.; Fleisch, H. Aggregation of hydroxyapatite crystals. Biochim. Biophys. Acta 1976, 451, 549-559. [CrossRef]

47. Liu, Y.; Wang, W.; Wang, A. Effect of dry grinding on the microstructure of palygorskite and adsorption efficiency for methylene blue. Powder Technol. 2012, 225, 124-129. [CrossRef]

48. Wu, M.; Bi, E. Stability of Artificial Nano-Hydroxyapatite in the Presence of Natural Colloids: Influence of Steric Forces and Chargeability. J. Environ. Qual. 2019, 48, 1100-1108. [CrossRef]

49. Lin, T.J.; Heinz, H. Accurate Force Field Parameters and pH Resolved Surface Models for Hydroxyapatite to Understand Structure, Mechanics, Hydration, and Biological Interfaces. J. Phys. Chem. C 2016, 120, 4975-4992. [CrossRef]

50. Lee, M.G.; Yi, G.; Ahn, B.J.; Roddick, F. Conversion of Coal Fly Ash into Zeolite and Heavy Metal Removal Characteristics of the Products. Korean J. Chem. Eng. 2000, 17, 325-331. [CrossRef] 